\title{
A SIMPLE METHOD FOR THE PREPARATION OF LUMINAL EPITHELIAL AND STROMAL CELLS FROM RAT UTERUS
}

\author{
P. J. HEALD, * A. D. T. GOVAN $\dagger$ AND J. E. O'GRADY* \\ *M.R.C. Group for Research in Biochemistry of Reproduction, \\ Department of Biochemistry, Royal College Building, and \\ $\dagger$ Department of Obstetrics and Gynaecology, Royal Maternity Hospital, Glasgow
}

(Received 18th September 1974)

Summary. An apparatus and procedure is described permitting the ready separation of luminal epithelial and stromal cells (together with the glands) from the rat uterus.

During the course of investigations on the biochemical changes in rat uterine tissue in relation to the initiation of the decidual response (Heald, 1973; O'Grady, Heald \& Moffat, 1974), it became increasingly apparent that there would be considerable advantage in having separate preparations of luminal epithelial cells and stromal cells available for study. After examining several different approaches to obtain such preparations the method described below was finally adopted.

The apparatus used is shown in Pl. 1, Fig. 1. The critical features were that the bottom flat surface of the tube was made from a disc of optically flat glass whilst the plunger was also cut flat and polished smooth thus presenting a flat surface to the optically flat base. Each plunger was tested for flatness by applying a small drop of dye to the surface and ensuring that vertical pressure against the base of the apparatus results in an even spread of the dye over the entire surface of the plunger. Plungers which did not meet these requirements were discarded.

Both glass and Teflon plungers have been used. Those made from Teflon were machined from solid rod and threaded to take a rod of stainless steel to the top of which a small handle or knob is fitted. Plungers made from glass were fire-polished to avoid sharp edges and were fitted with a plastic handle.

The clearance between the walls of the vessel and the plunger was about 0.5 $\mathrm{mm}$. Clearances greater than this resulted in the uterine tissue slipping from under the plunger and up the side of the tube, while too tight a fit made operation of the plunger difficult.

Although the precise depth of the plunger was not critical, a measurement of 20 to $25 \mathrm{~mm}$ with the above clearance ensured that the lower surface remained essentially parallel with the base of the vessel during operation.

The uterus was removed from the animal, placed on a filter paper moistened with medium or saline $(0.9 \% \mathrm{NaCl}, \mathrm{w} / \mathrm{v})$, and trimmed free from fat and 
mesentery. The horns were separated and slit open with fine scissors. Each horn was rapidly weighed on a torsion balance and replaced on a moistened filter paper contained in a Petri dish resting on ice. The uterus was then cut into segments sufficiently long (about $1.5 \mathrm{~cm}$ ) to rest flat on the bottom of the glass apparatus. About $2.0 \mathrm{ml}$ ice-cold medium, (usually $0.25 \mathrm{M}$-sucrose, $0.3 \mathrm{~mm}$ $\mathrm{CaCl}_{2}$ ) was pipetted into the tube which was kept on ice and a piece of tissue was dropped into the tube. The tissue usually settled to the bottom but if it adhered to the side of the vessel, it could be gently pushed down with the plunger before the next stage. When the tissue was in place, the tube was set upright on the bench, and the pestle carefully placed vertically over the uterine segment. The tissue was then squeezed gently but firmly (downward pressure, 1.5 to 2.0 $\mathrm{kg}$ ), twice or thrice with the pestle held upright. The squeezing removed the epithelial cells as sheets and this vertical pressure only was required. Pressure had to be gentle and the pestle could not be rotated, otherwise the shearing stress so produced also removed some of the stromal cells. With a little practice the correct 'feel' of the pestle was soon obtained.

After squeezing, the tissue was removed with a spatula or glass rod and was normally rinsed by floating in fresh medium in a small porcelain dish before transferring to a Potter-Elvehjem type homogenizing tube for preparation of the stromal cell suspension. The entire operation from dropping the uterine segment into the tube and its removal after squeezing took approximately $10 \mathrm{sec}$. The suspension of epithelial cells was poured from the tube through the spout (Pl. 1, Fig. 1). The cavity was used for decanting cells from the tissue residue when desired.

The uterine tissue, essentially free from epithelium, was placed in a PotterElvehjem type homogenizing tube in approximately $2.0 \mathrm{ml}$ medium and, using the Teflon pestle appropriate to the tube diameter, was then pressed and sheared three times by hand. The most effective movement of the pestle was a backwards and forwards rotation by hand, repeated twice, with the pestle being lifted slightly before the next downward pressure. This procedure almost completely removed the stromal cells together with the glands. The remaining tissue (myometrium) was then removed with a spatula and rinsed in fresh medium and either retained for analysis or discarded as desired.

Several pieces of uterus could be processed in the same solution in the 'squeezer' and in the homogenizer. In practice, two uterine horns were normally processed in $2.0 \mathrm{ml}$ medium.

Suspensions of epithelial and stromal cells were centrifuged and the packed cells were smeared on slides, fixed in absolute alcohol and stained by Papanicoloau's method.

\section{EXPLANATION OF PLATE 1}

Fig. 1. Photograph of the tissue squeezing apparatus for removal of epithelial cells from the uterine lumen of the rat. (A) Glass tube with B29 joint, (B) glass plunger, with plastic handle, (G) Teflon plunger.

Fig. 2. Rat uterine tissue section before treatment. $\times 70$.

Fig. 3. Section of rat uterine tissue after two squeezes in the tissue press. The epithelial layers have been largely removed, $\times 70$. 

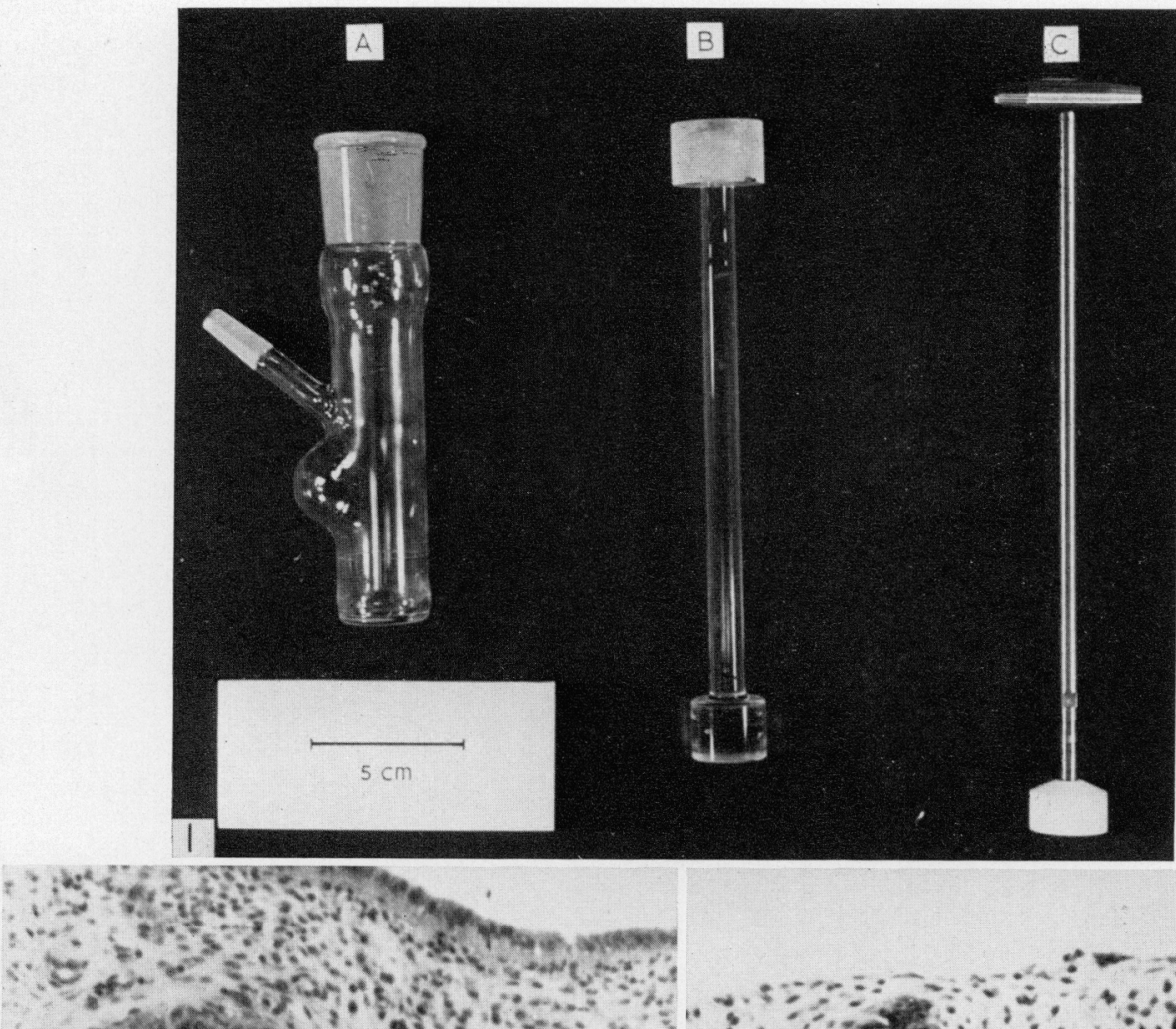
n. +

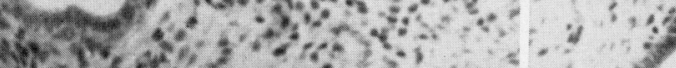

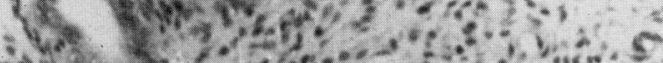

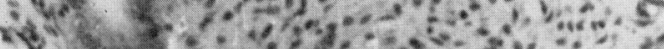

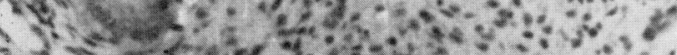

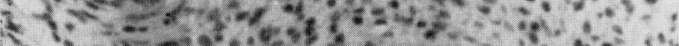

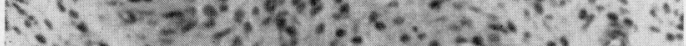

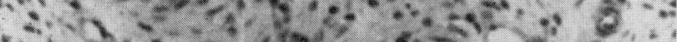

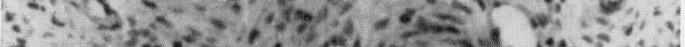

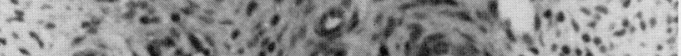

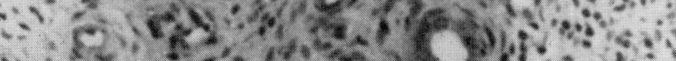

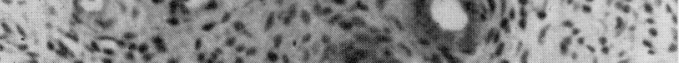

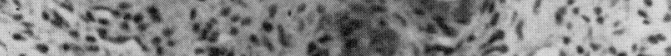
$\therefore$ ato.

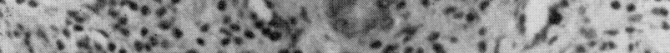
1.

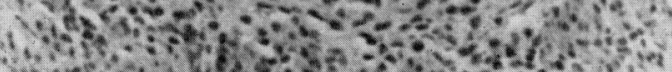

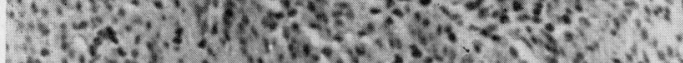
Why

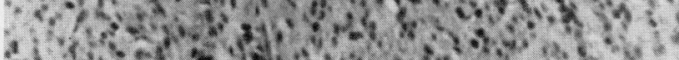

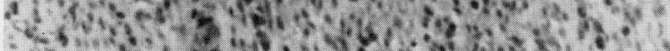

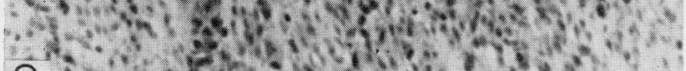

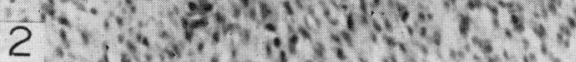


PLATE 2
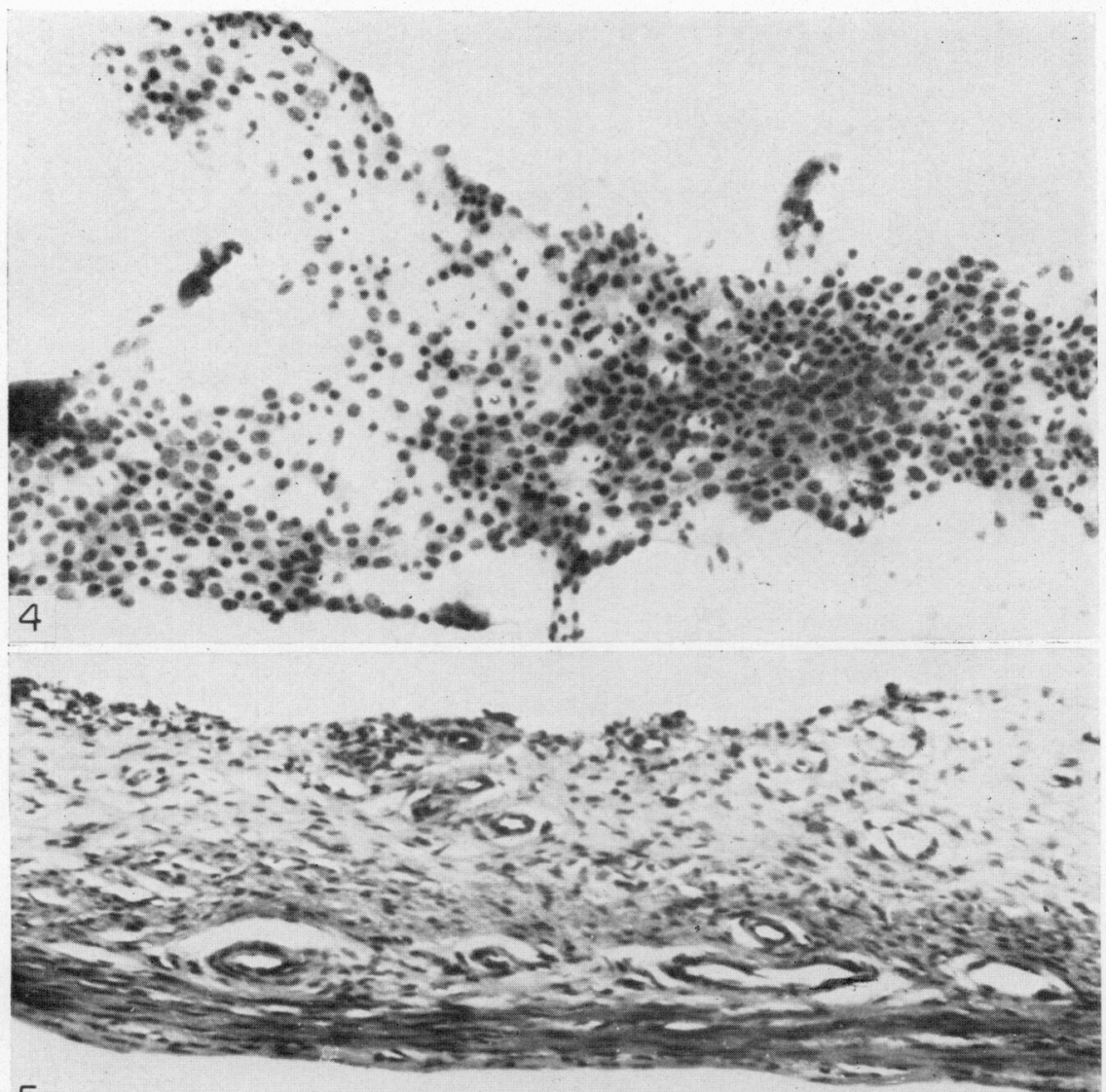

5
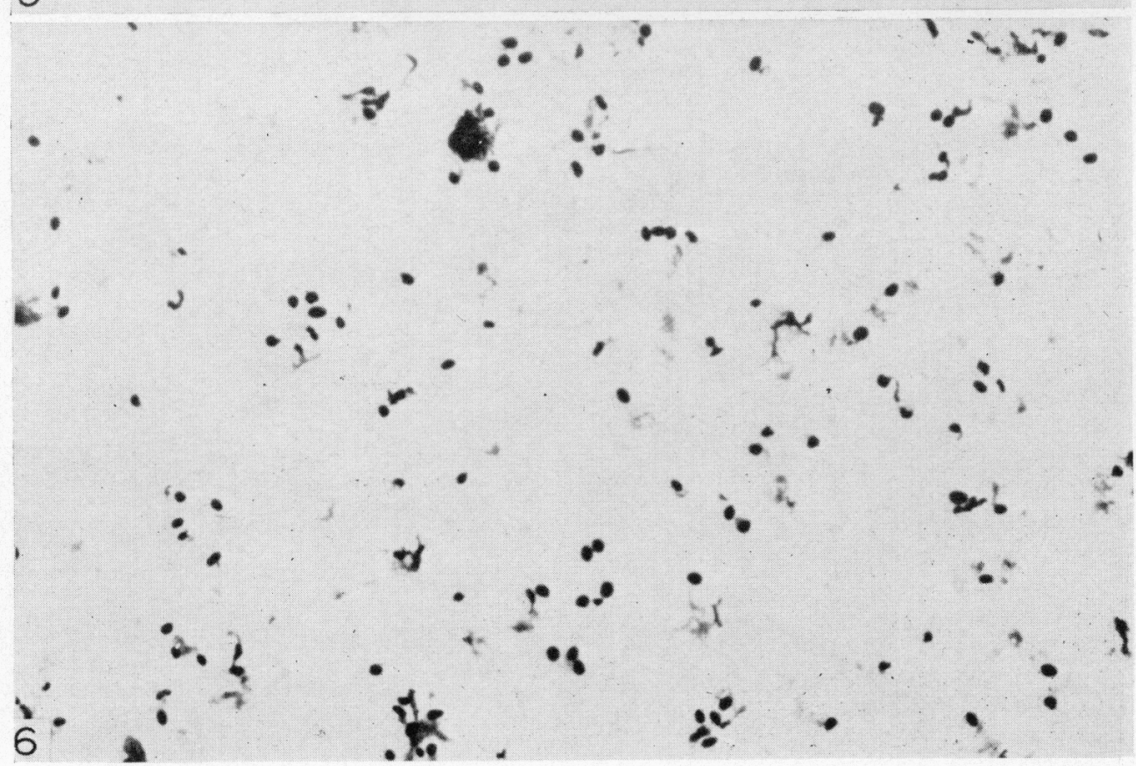

(Facing p. 595) 
Whole uterus (PI. 1, Fig. 2) and the residual myometrium was fixed in neutral formalin sectioned and stained with haematoxylin and eosin.

Initial attempts to obtain epithelial cells by scraping the luminal surface with a scalpel blade or the edge of a glass slide produced mixtures of epithelial and stromal cells and left much of the stroma crushed. Attempts were also made to remove epithelium by very gently homogenizing in the Potter-Elvehjem homogenizer. Although this method has been described by Smith, Martin, King \& Vertes (1970) for producing epithelial cells, in our hands most of the stroma was removed with the epithelium. Epithelial layers could be obtained by touching the surface of the lumen with a clean glass slide, but such preparations proved too difficult to remove from the slide, dried rapidly, and did not result in the removal of all the epithelium from the luminal surface.

The procedure finally adopted yielded preparations that appeared satisfactory.

The epithelial layers were removed as sheets of cells (Pl. 1, Fig. 3) leaving the stromal layers virtually untouched (Pl. 2, Fig. 4). The stromal cells were obtained as suspensions virtually free from visible surface epithelial cells but containing the glands (Pl. 2, Fig. 5). This appears to be an inherent problem of the present method, but, since the glands penetrate the stromal layers, any removal of the stroma necessarily removes the glands. It has not proved possible, so far, by the use of differential centrifugation, to separate the two.

Examination of the tissue after the final homogenization (Pl. 2, Fig. 6) revealed that the bulk of the stroma had been removed, leaving the circular muscle and remaining myometrium untouched.

The procedure was highly reproducible and has been in use by several workers in these laboratories for some months in the preparation of cells for metabolic study. As a matter of sound laboratory practice, however, it is recommended that the preparations obtained by each worker be checked histologically to ensure that the technique is yielding consistent results before a programme of work is initiated.

We thank the Medical Research Council for a Grant to one of us (P.J.H.) and Dr R. J. B. King who drew our attention to the possibilities of the 'tissue squeezer' and who was instrumental in supplying us with the initial apparatus.

\section{REFERENCES}

Smith, J. A., Martin, L., King, R. J. B. \& Vertes, M. (1970) Effects of oestradiol-17 $\beta$ and progesterone on total and nuclear-protein synthesis in epithelial and stromal tissues of mouse uterus, and of progesterone on the ability of these tissues to bind oestradiol-178. Biochem. 7. 119, 773-784.

Heald, P.J. (1973) Uterine metabolism in early pregnancy in the rat. Biochem. Soc. Trans. 1, 487-491.

O'Grady, J. E., Moffat, G. E. \& Heald, P. J. (1974) Uterine RNA metabolism in early stages of pregnancy in the rat. $\mathcal{F}$. Endocr. 61 , i-ii.

EXPLANATION OF PLATE 2

FIG. 4. Rat uterine epithelial cells as recovered after two squeezes. The cells are clearly obtainable as typical sheets. $\times 80$.

FIG. 5. Rat uterine tissue following treatment to remove the stromal cellular layer. Most of the stromal cells have been removed, leaving the myometrium intact. $\times 80$.

Fig. 6. Stromal cellular preparation of rat uterine tissue. $\times 80$. 